\title{
Protective action of a hexane crude extract of Pterodon emarginatus fruits against oxidative and nitrosative stress induced by acute exercise in rats
}

\author{
Fernanda BA Paula1 ${ }^{1}$, Cibele MCP Gouvêa ${ }^{2}$, Patrícia P Alfredo ${ }^{3}$ and \\ Ione Salgado*4
} \begin{abstract}
de Campinas (UNICAMP), Campinas, SP, 13083-970, Brazil
Email: Fernanda BA Paula - fbapaula@yahoo.com.br; Cibele MCP Gouvêa - cibelegouvea@hotmail.com;

Patrícia P Alfredo - patriciaalfredo@yahoo.com.br; Ione Salgado* - ionesm@unicamp.br

* Corresponding author
\end{abstract}

Address: ${ }^{1}$ Departamento de Análises Clínicas e Toxicológicas, Escola de Farmácia e Odontologia de Alfenas (EFOA), Alfenas, MG, 37130-000, Brazil, ${ }^{2}$ Departamento de Ciências Biológicas, Escola de Farmácia e Odontologia de Alfenas (EFOA), Alfenas, MG, 37130-000, Brazil, ${ }^{3}$ Faculdade de Fisioterapia, Universidade de Alfenas, MG, 37130-000, Brazil and ${ }^{4}$ Departamento de Bioquímica, Instituto de Biologia, Universidade Estadual

BMC Complementary and Alternative Medicine 2005, 5:17 doi:10.1186/1472- Accepted: 17 August 2005 6882-5-17

This article is available from: http://www.biomedcentral.com/I472-6882/5/17

(c) 2005 Paula et al; licensee BioMed Central Ltd.

This is an Open Access article distributed under the terms of the Creative Commons Attribution License (http://creativecommons.org/licenses/by/2.0), which permits unrestricted use, distribution, and reproduction in any medium, provided the original work is properly cited.

\begin{abstract}
Background: The aim of the present work was to evaluate the effect of a hexane crude extract (HCE) of Pterodon emarginatus on the oxidative and nitrosative stress induced in skeletal muscle, liver and brain of acutely exercised rats.

Methods: Adult male rats were subjected to acute exercise by standardized contractions of the tibialis anterior (TA) muscle $(100 \mathrm{~Hz}, 15 \mathrm{~min}$ ) and treated orally with the HCE (once or three times with a fixed dose of $498 \mathrm{mg} / \mathrm{kg}$ ), before and after acute exercise. Serum creatine kinase activity was determined by a kinetic method and macrophage infiltration by histological analyses of TA muscle. Lipid peroxidation was measured as malondialdehyde (MDA) levels. Nitric oxide production was evaluated by measuring nitrite formation, using Griess reagent, and nitrotyrosine was assessed by western blotting.

Results: Serum creatine kinase activities in the controls (III U/L) increased I $\mathrm{h}$ after acute exercise $(443 \mathrm{U} / \mathrm{L})$. Acute exercise also increased the infiltration of macrophages into TA muscle; lipid peroxidation levels in TA muscle (967\%), liver (55.5\%) and brain (108.9\%), as well as the nitrite levels by $90.5 \%, 30.7 \%$ and $60 \%$, respectively. The pattern of nitrotyrosine formation was also affected by acute exercise. Treatment with HCE decreased macrophage infiltration, lipid peroxidation, nitrite production and nitrotyrosine levels to control values.

Conclusion: Acute exercise induced by functional electrical stimulation in rats resulted in increase in lipid peroxidation, nitrite and nitrotyrosine levels in brain, liver and skeletal muscle. The exercise protocol, that involved eccentric muscle contraction, also caused some muscle trauma, associated with over-exertion, leading to inflammation. The extract of $P$. emarginatus abolished most of these oxidative processes, thus confirming the high antioxidant activity of this oil which infusions are used in folk medicine against inflammatory processes.
\end{abstract}




\section{Background}

Although exercise has salutary effects, strenuous or unaccustomed physical exercise can cause morphological insult to the myocardial and skeletal muscle involved in the activity, as well as to others organs [1]. Tissue damage resulting from acute or chronic exercise ranges from considerable fiber disruption to subcellular damage $[2,3]$. Such damage may arise from oxidative stress caused by reactive oxygen species (ROS), which elicit different responses, depending on the organ or tissue and its levels of endogenous antioxidant [1]. In response to eccentric contraction-induced muscle damage, neutrophils and macrophages migrate to the site, infiltrate the muscle tissue, activate cytokines, and produce additional ROS $[4,5]$. These activities may overwhelm the natural antioxidant defenses of the cell and lead to lipid peroxidation and delayed-onset muscle damage [4,5]. Increased levels of lipid peroxidation have been detected after sprint exercise in blood samples from sprint-trained athletes [6] and in the skeletal muscle of rats after sprint and acute exercise $[3,5]$.

Acute exercise also increases nitric oxide (NO) formation and NO synthase (NOS) activity [7,8]. Reid [9] proposed that, in addition to ROS, NO may play an important role in skeletal muscle, and that muscles involved in repetitive contraction may produce sufficient $\mathrm{NO}$ to influence the oxidant-antioxidant balance. NO has been implicated in the metabolic control of muscle by its effects on blood delivery, glucose uptake, oxidative phosphorylation, contractility, and excitation-contraction coupling [10]. However, exposure to reactive oxygen and nitrogen species (RONS) may cause lipid peroxidation in cell membranes, which in turn may generate species that damage cell proteins and promote their degradation [11]. These actions may impair the performance, integrity and metabolism of muscle cells [4]. In addition to the increase in lipid peroxidation following acute exercise, the effects of nitration need to be considered, especially since tyrosine nitration is frequently linked to altered protein function during inflammatory conditions [12]. Protein nitration has been suggested to be a final product of the highly reactive nitrogen oxide intermediates(e.g. peroxynitrite) formed in reactions between $\mathrm{NO}$ and oxygen-derived species such as superoxide. However, Gunther et al. [13] described a mechanism for NO-dependent tyrosine nitration that does not require the formation of highly reactive nitrogen oxide intermediates such as peroxynitrite or nitrogen dioxide. Peroxidases can also oxidize nitrite to nitrogen dioxide radical, which can cause nitration of tyrosine and tyrosine residues in proteins [14].

Pterodon emarginatus Vog. (Leguminosae, Papilonaceae), popularly known as sucupira branca, is a native tree species widely distributed throughout central Brazil, in the states of Goiás, Minas Gerais and São Paulo. Sucupira infusions are used in folk medicine for the treatment of rheumatism, sore throats and back-bone problems [15]. Pterodon seed oil has cercaricidal activities [16], an acute anti-inflammatory action in rats [17] and an analgesic effect in mice [18]. The seed oil contains diterpenes and furanditerpenes [19]. The most ubiquitous furanditerpene of $P$. emarginatus fruits is $6 \alpha, 7 \beta$-di-hydroxyvouacapan-17 $\beta$-oic acid [19], the anti-inflammatory activity of which has been evaluated in rodent experimental models of paw edema induced by carrageenin and nystatin $[17,20]$.

Although there have been a number of reports on the antiinflammatory activity of Pterodon oil, there has been no investigation of its antioxidant activity. The aim of the present work was to investigate the antioxidant activity and the effect on nitrite production of hexane crude extract of $P$. emarginatus fruits in acutely exercised rats.

\section{Methods \\ Animals}

The present study is in compliance with the principals and guidelines of the Brazilian Institute for Animal Experimentation (COBEA) and it had institutional ethical approval by the Ethics Committee for Animal Research, Escola de Farmácia e Odontologia de Alfenas/Centro Universitário Federal (Efoa/Ceufe; Permission: 15/04/2004).

Male Wistar rats $(270 \pm 20 \mathrm{~g})$ were obtained from the Efoa/Ceufe. The rats were housed in a temperature-controlled room on a $12 \mathrm{~h}$ light/dark schedule with food and water available ad libitum. The rats were allocated to six experimental groups: (1) rested control group; (2) acutely exercised group; (3) rested group treated with $P$. emarginatus hexane crude extract (HCE); (4) acutely exercised group treated with the P. emarginatus HCE $0.5 \mathrm{~h}$ before exercise, (5) acutely exercised group treated with the $P$. emarginatus HCE $0.5 \mathrm{~h}$ after exercise and (6) acutely exercised group treated with three administrations of HCE given at $24 \mathrm{~h}, 12 \mathrm{~h}$ and $0.5 \mathrm{~h}$ before exercise. The rats were sacrificed $1 \mathrm{~h}, 6 \mathrm{~h}$ and $48 \mathrm{~h}$ after HCE administration (group 3) or after acute exercise (groups 2, 4-6). For the determination of CK levels the rats were sacrificed immediately or $1 \mathrm{~h}, 6 \mathrm{~h}$ and $48 \mathrm{~h}$ after exercise. For each treatment, 8-10 rats were used, as specified in the figure legends.

\section{Acute exercise}

The rats were acutely exercised using functional electrical stimulation to produce standardized repetitive activation of the fast tibialis anterior (TA) muscle, according to Matsuura et al. [21] with modifications. Briefly, the animals were boxed and two square electrodes $\left(1 \mathrm{~cm}^{2}\right)$ were then fixed on the skin of their right legs at proximal and distal 
ends of the TA muscle. TA muscle was stimulated electrically (Neurodyn II-Ibramed) through an electrode with 10 $s$ square wave biphasic pulses and interpulse intervals of $10 \mathrm{~s}$ of $5 \mathrm{~V}$ for $10 \mathrm{~min}$. Stimulation frequency was $100 \mathrm{~Hz}$, with an on-off ratio of 1:1.

\section{Plant extract preparation and administration to rats}

Pterodon emarginatus Vog. fruits were harvested in the state of Minas Gerais, Brazil. A crude hexane extract (HCE) was prepared according to Carvalho et al. [20]. Briefly, the fruits were ground in the presence of hexane using an industrial blender and then placed in a percolator at room temperature and successively washed with hexane. The extraction liquid was collected, filtered and concentrated by rotatory evaporation under reduced pressure. The resulting HCE had an oily characteristic and a density of $0.98 \mathrm{~g} / \mathrm{mL}$ and was administered orally (by gavage) to the rats, in one or three doses at $498 \mathrm{mg} / \mathrm{kg}$ each.

\section{Serum creatine kinase (CK) activity and lactate level determinations}

Blood samples were obtained by cardiac punction from anesthetized rats either before or after the acute exercise. The serum CK activity was determined by a colorimetric assay (CK-NAC kit, Bayer), at $340 \mathrm{~nm}$, and was expressed in $\mathrm{U} / \mathrm{L}$, where $1 \mathrm{U}$ resulted in the phoshorylation of 1 mmol of creatine per min at $25^{\circ} \mathrm{C}$. Serum lactate concentrations were determined by a colorimetric assay at 550 $\mathrm{nm}$, using lactate oxidase [22].

\section{Histological analysis}

The tibialis anterior (TA) muscle was removed from all rats and fixed in $4 \%(\mathrm{v} / \mathrm{v})$ formalin, embedded in paraffin, cut longitudinally into $5 \mu \mathrm{m}$ sections and stained with hematoxylin-eosin. The density of macrophages and the extent muscle fiber damage were estimated by point counting morphometry, using 15 randomly selected fields of $0.625 \mathrm{~mm}^{2}$ per section.

\section{Measurement of TBARS in brain, liver and TA muscle}

As an index of oxidative damage, lipid peroxidation was evaluated by using the level of thiobarbituric acid-reactive substances (TBARS) test [23]. Brain, liver and TA muscle were homogenized in four volumes of $0.1 \mathrm{M}$ phosphate buffered saline (PBS) and centrifuged at 3,000 $g, 4^{\circ} \mathrm{C}$, for $10 \mathrm{~min}$. Aliquots $(0.5 \mathrm{ml})$ of each homogenate were mixed with $0.5 \mathrm{~mL}$ of a solution containing $2 \%$ thiobarbituric acid, $0.5 \mathrm{~mL}$ of $25 \% \mathrm{HCl}$ and $45 \mu \mathrm{L}$ of $2 \%$ BHT (butylated hydroxytoluene). The mixtures were heated at $95^{\circ} \mathrm{C}$ for $10 \mathrm{~min}$ and then centrifuged. The supernatant was transferred to a quartz cuvette and the absorption was measured at $532 \mathrm{~nm}$. The absorption values were transformed into concentrations of MDA using 1,1,3,3-tetraethoxypropane (TEP) as standard.

\section{Determination of nitrite in brain, liver and TA muscle}

Nitrite is a stable end product of NO, and its concentration was determined by the Griess method [see [24]]. Brain, liver and TA muscle were homogenized in four volumes of $30 \mathrm{mM}$ Tris-HCl buffer, $\mathrm{pH} \mathrm{6.8,} \mathrm{containing} 5 \mathrm{mM}$ EDTA, $250 \mathrm{mM}$ sucrose, $30 \mathrm{mM} \mathrm{KCl,} \% \beta$-mercaptoethanol, PMSF $(100 \mu \mathrm{g} / \mathrm{mL})$, benzamidine $(5 \mu \mathrm{g} / \mathrm{ml})$, aprotinin $(2 \mu \mathrm{g} / \mathrm{mL})$ and leupeptin $(2 \mu \mathrm{g} / \mathrm{mL})$, and then centrifuged $\left(12,000 \times g, 4^{\circ} \mathrm{C}, 15 \mathrm{~min}\right)$. Protein concentrations were determined by the Coomassie blue dye-binding method [25] using bovine serum albumin as standard. Aliquots $(1.0 \mathrm{~mL})$ of the homogenates were removed and diluted with $1.0 \mathrm{~mL}$ of Griess reagent (1\% sulphanilamide, 2\% phosphoric acid and $0.1 \%$ naphthyl ethylene diamine dihydrochloride). The absorbance of the chromophore formed during diazotization of the nitrite with sulphanilamide and subsequent coupling with naphthylethelene diamine was measured at $545 \mathrm{~nm}$. Appropriate blanks and controls were run in parallel.

\section{Western blotting analysis}

Aliquots $(30 \mu \mathrm{g})$ of protein from brain, liver and TA muscle were run on $9 \%$ gels using sodium dodecyl sulfatepolyacrylamide gel electrophoresis and were electrophoretically transferred overnight, at $4{ }^{\circ} \mathrm{C}$, to nitrocellulose membranes in $20 \mathrm{mM}$ Tris, $192 \mathrm{mM}$ glycine and 20\% methanol. The membranes were blocked for $1 \mathrm{~h}$ at $4^{\circ} \mathrm{C}$ in Tris-buffered saline containing 30\% Tween 20 and 50\% Triton X-100 (TBSTT) with 1\% BSA. The blots were then incubated for $2 \mathrm{~h}$ with anti-nitrotyrosine antibody (1:1000) (Sigma) in TBSTT with $1 \%$ BSA at room temperature. The membranes were washed five times in TBSTT with $0.1 \%$ BSA, and incubated for $1 \mathrm{~h}$ with peroxidaseconjugated anti-goat IgG $(1: 2500)$ (Amersham) in TBSTT with $1 \%$ BSA at room temperature. The blots were again washed five times in TBSTT with $0.1 \%$ BSA and then visualized using an Enhanced Chemiluminescence (ECL) detection system (Amersham) [26].

\section{Statistical analysis}

The results were expressed as the means \pm SE of the number of measurements (independent experiments) shown. Statistical comparisons were done using ANOVA and the Tukey-Kramer test, with $P<0.05$ indicating significance.

\section{Results}

Acute exercise increases serum creatine kinase activity

Serum creatine kinase (CK) activity increased in exercised rats. Maximum CK activity was seen $1 \mathrm{~h}$ after acute exercise and remained elevated for up $48 \mathrm{~h}$ after exercise (Fig. $1)$. The serum lactate concentration also increased in the exercised rats $(75.36 \pm 1.48 \mathrm{mg} / \mathrm{dL}, \mathrm{n}=8)$ when compared to the controls $(54.67 \pm 3.06 \mathrm{mg} / \mathrm{dL}, \mathrm{n}=8)$. 


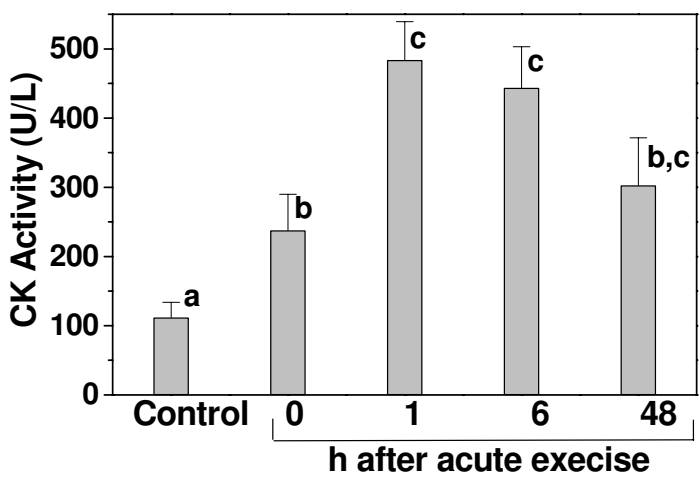

Figure I

Effect of acute exercise on serum creatine kinase (CK) activity. The CK levels were determined in rested control and after acute exercise, at the indicated times. The results are the mean \pm SE of $8-10$ rats per treatment. Significance was determined with one-way ANOVA followed by the Tukey-Kramer test. Columns with different letters differed significantly $(p<0.05)$.

\section{HCE reduces macrophage infiltration in TA muscle} induced by acute exercise

As shown in Fig. 2, intense exercise increased the infiltration of macrophages into the tibialis anterior (TA) muscle. Higher density was already observed $6 \mathrm{~h}$ after exercise and after $48 \mathrm{~h}$ it was still elevated. For our study, we have chosen an exercise protocol that involved a polymetric (eccentric) muscle component. Untrained exercised rats therefore experience both oxidative and polymetric stress, with the latter causing some muscle trauma, associated with over-exertion, leading to inflammation. Oral administration of the HCE alone did not affect the density of macrophages in TA muscle. However, the increased density of macrophages, seen in TA muscle of acutely exercised rats was significantly reduced, when the HCE was administered $0.5 \mathrm{~h}$ before or $0.5 \mathrm{~h}$ after acute exercise. When the HCE was administered $0.5 \mathrm{~h}$ after acute exercise, cell density of macrophages reduced to almost control values $48 \mathrm{~h}$ after exercise indicating its effectiveness against the delayed-onset of muscle trauma.

\section{HCE reduces lipid peroxidation in TA muscle, brain and liver induced by acute exercise}

Lipid peroxidation, evaluated by TBARS formation (MDA), was assessed in brain, liver and tibialis anterior muscle. Lipid peroxidation increased after acute exercise in all of the tissues analyzed (Fig. 3A). The highest TBARS formation was seen in TA muscle, with an increase of

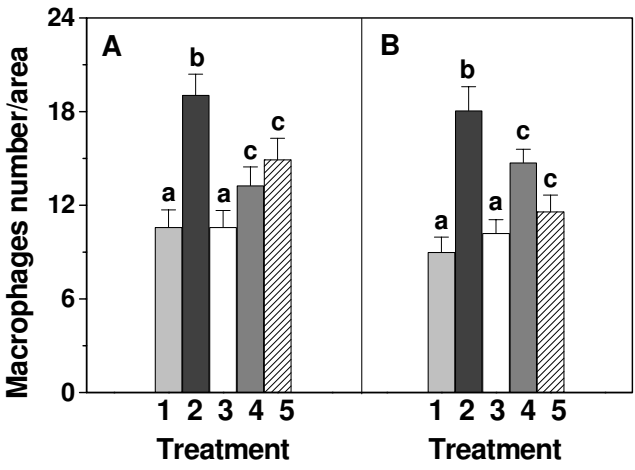

Figure 2

Effect of HCE (498 $\mathrm{mg} / \mathrm{Kg})$, administrated orally to acute exercised rats, on the density of macrophages in the tibialis anterior muscle. The number of cells per $0.625 \mathrm{~mm}^{2}$ area was determined in muscles of rested control rats ( 1$)$; acutely exercised rats (2); rested rats treated with HCE (3); acutely exercised rats treated with HCE $0.5 \mathrm{~h}$ before exercise (4) and acutely exercised rats treated with HCE $0.5 \mathrm{~h}$ after exercise (5). The number of cells was determined at $6 \mathrm{~h}(\mathrm{~A})$ and $48 \mathrm{~h}(\mathrm{~B})$ after acute exercise. Each column shows the mean \pm SE of I 5 randomly selected fields of 8-10 rats. Significance was determined with one-way ANOVA followed by the Tukey-Kramer test. Columns with different letters differed significantly $(p<0.05)$.

$967 \%$, followed by brain (109\%) and liver (55.5\%). The time at which maximum lipid peroxidation was seen after exercise differed among the tissues - $48 \mathrm{~h}$ in brain and 6 $\mathrm{h}$ in liver and TA muscle. In TA muscle, the MDA levels were still elevated after 48 h (Fig. 3A).

Based on the results shown in figure 3A, we studied the effects of the HCE on lipid peroxidation in TA muscle $6 \mathrm{~h}$ and $48 \mathrm{~h}$ after acute exercise. In brain and liver, the effects of HCE were analyzed at $48 \mathrm{~h}$ and $6 \mathrm{~h}$ after acute exercise, respectively. The effect of HCE on lipid peroxidation was assessed by administering the extract $0.5 \mathrm{~h}$ before and 0.5 $\mathrm{h}$ after acute exercise. These treatments completely decreased lipid peroxidation in brain and liver tissues (Fig. 3B). However, in TA muscle, the HCE was effective in reducing lipid peroxidation only $48 \mathrm{~h}$ after acute exercise; the levels of MDA were still elevated $6 \mathrm{~h}$ after acute exercise (Fig. 3C). Then we examined the effect of three administrations of a fixed dose $(498 \mathrm{mg} / \mathrm{Kg})$ of HCE given $24 \mathrm{~h}, 12 \mathrm{~h}$ and $0.5 \mathrm{~h}$ before acute exercise. This protocol significantly reduced the TBARS in TA muscle $6 \mathrm{~h}$ after exercise (Fig. 3C), indicating that this treatment was more 

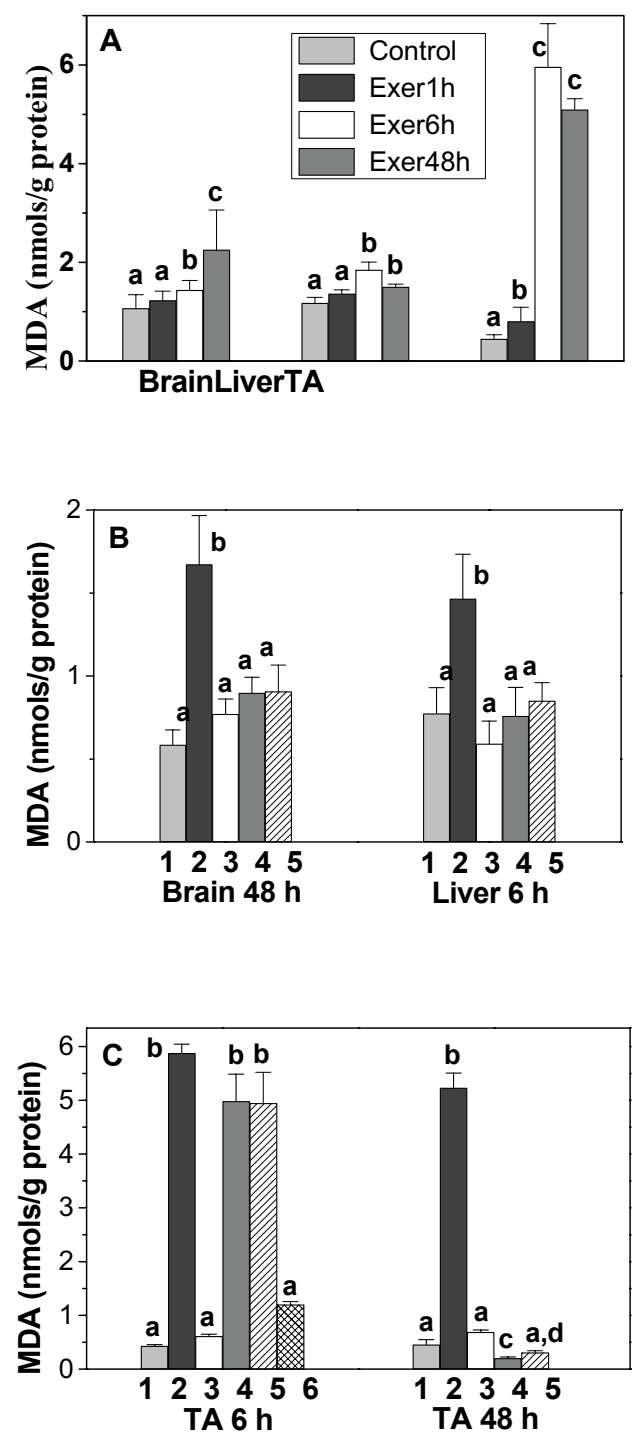

Figure 3

Effect of the HCE from $P$. emarginatus on brain, liver and TA muscle lipid peroxidation after acute exercise. (A) TBARS were determined in tissue homogenates of rested control rats and I h (Exer I h), $6 \mathrm{~h}$ (Exer $6 \mathrm{~h}$ ) and 48 $\mathrm{h}($ Exer $48 \mathrm{~h}$ ) after acute exercise. TBARS were determined in brain and liver (B) and in TA muscle (C) homogenates of rested control rats (I); acutely exercised rats (2); rested rats treated with HCE (3); acutely exercised rats treated with HCE 0.5 h before exercise (4), acutely exercised rats treated with HCE $0.5 \mathrm{~h}$ after exercise (5) and acutely exercised rats treated with HCE 24, 12 and $0.5 \mathrm{~h}$ before exercise (6). TBARS levels were estimated at $48 \mathrm{~h}$ (brain), $6 \mathrm{~h}$ (liver) and 6 $\mathrm{h}$ and $48 \mathrm{~h}$ (TA muscle) after exercise, as indicated. Each column shows the mean \pm SE of 8-10 rats. Significance was determined with one-way ANOVA followed by the TukeyKramer test. Columns with different letters differed significantly $(p<0.05)$. effective in reducing the lipid peroxidation induced by acute exercise in TA muscle, when compared with a single treatment protocol.

\section{HCE reduces nitric oxide levels in TA muscle, brain and liver increased by acute exercise}

As shown in Fig. 4A, the basal nitrite concentration in TA muscle was seven and six times greater than in brain and liver, respectively. Despite this difference, acute exercise increased the nitrite production by $60.0 \%, 30.7 \%$ and $90.5 \%$ in brain, liver and TA muscle, respectively. The maximum nitrite levels in brain, liver and TA muscle were observed $48 \mathrm{~h}, 6 \mathrm{~h}$ and $1 \mathrm{~h}$ after exercise, respectively (Fig. $4 \mathrm{~A})$. When HCE was administered $0.5 \mathrm{~h}$ before or $0.5 \mathrm{~h}$ after acute exercise, the nitrite production decreased to basal levels in all of the tissues (Fig. 4B). The effects of the HCE on nitrite production were assessed at $1 \mathrm{~h}$ (TA muscle), $6 \mathrm{~h}$ (liver) and $48 \mathrm{~h}$ (brain) after exercise because at those times we found the maximal nitrite production in the respective tissues (Fig. 4A). The effect of HCE was similar, regardless of whether it was administered three times or only once (data not shown).

\section{HCE prevents nitration of brain and muscle proteins increased by acute exercise}

Western blot analysis using an antibody specific for nitrotyrosine revealed different staining patterns for brain ( 48 $\mathrm{h}$ after exercise), liver ( $6 \mathrm{~h}$ after exercise) and TA muscle (1 $\mathrm{h}$ after exercise) that were consistent with the nitration of one or more tyrosine residues on proteins (Fig. 5). In the brain, two more bands ( 66 and $51 \mathrm{kDa}$ ) were detected in the exercised rats. The administration of three doses of HCE $(498 \mathrm{mg} / \mathrm{kg}$ each), given $24 \mathrm{~h}, 12 \mathrm{~h}$ and $0.5 \mathrm{~h}$ before acute exercise, prevented the formation of these bands, indicating that the extract prevented exercise-induced nitrotyrosine formation in the brain. In liver, no nitrotyrosine was detected in the control or HCE administered rats, but in exercised rats three bands $(66,55$ and $45 \mathrm{kDa})$ were evident and the treatment with HCE did not prevent nitrotyrosine formation in this tissue. In TA muscle, a triplet band pattern and a band of $66 \mathrm{kDa}$ were seen in the control. These bands were less intense in the HCE administered rats. The exercised rats showed an intense band at $97 \mathrm{kDa}$, in addition to the $66 \mathrm{kDa}$ band and the triplet. In TA muscle from HCE-exercised rats, labeling of the $97 \mathrm{kDa}$ was abolished and the intensity of the triplet decreased, indicating that the extract prevented nitrotyrosine formation. The $97 \mathrm{kDa}$ band can be related to phagocyte activity in the TA muscle.

\section{Discussion}

In this work we examined the effects of an HCE from Pterodon emarginatus on the oxidative and nitrosative stress induced by acute exercise. Whereas a large number of studies have tested the effects of vitamins and minerals in 

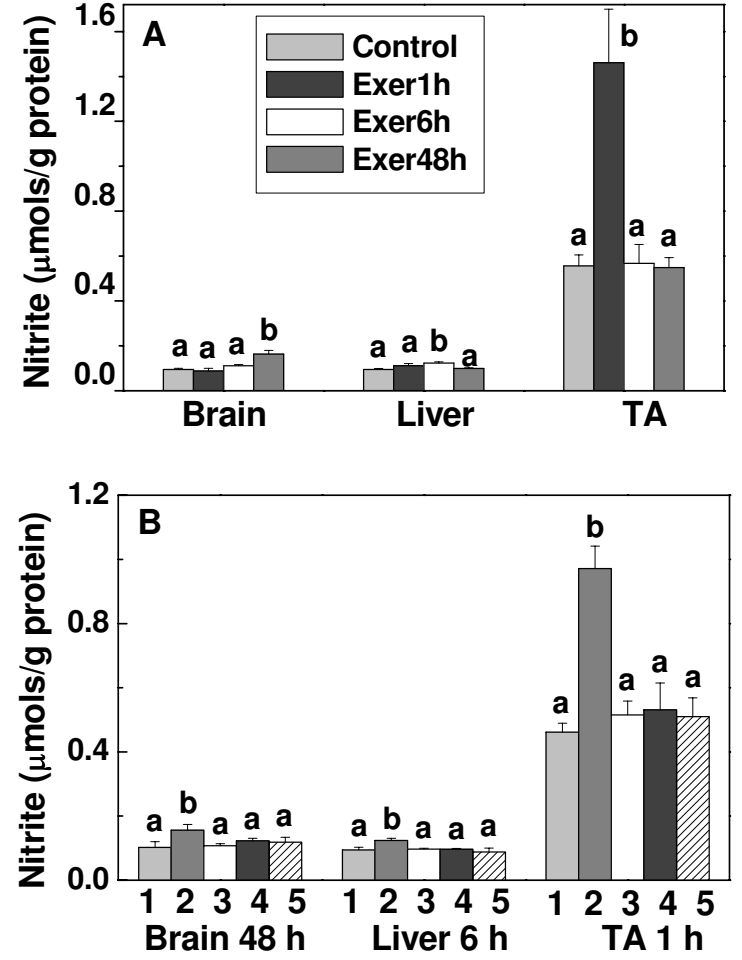

\section{Figure 4}

Effect of the HCE from $P$. emarginatus on nitrite levels in brain, liver and TA muscle after acute exercise. (A) Nitrite levels were estimated by the Griess reaction in tissue homogenates of rested control rats and at I $\mathrm{h}$ (Exer I h), $6 \mathrm{~h}$ (Exer $6 \mathrm{~h}$ ) and $48 \mathrm{~h}$ (Exer $48 \mathrm{~h}$ ) after exercise. (B) Nitrite was determined in tissue homogenates of rested control rats (I); acutely exercised rats (2); rested rats treated with HCE (3); acutely exercised rats treated with HCE $0.5 \mathrm{~h}$ before exercise (4) acutely exercised rats treated with HCE $0.5 \mathrm{~h}$ after exercise (5). Nitrite levels were estimated at I $\mathrm{h}$ (TA muscle), $6 \mathrm{~h}$ (liver) and $48 \mathrm{~h}$ (brain) after exercise. Each column shows the mean \pm SE of 8-10 rats. Significance was determined with one-way ANOVA followed by the TukeyKramer test. Columns with different letters differed significantly $(p<0.05)$.

preventing oxidation in exercise, there is little information on the effect of plant extracts on lipid peroxidation and nitric oxide formation during acute exercise.

An increase in serum CK and in neutrophil and macrophage infiltration after acute exercise has been reported in humans and animals [27-29]. However, there is controversy about the relationships between CK kinetics and the time at which the most prominent muscle cell damage occurs. The degree of muscle damage is considered to be proportional to muscle loading [4]. Our results showed that CK activity increased after acute exercise, with maximum activity after $1 \mathrm{~h}$ and remained elevated for at least $48 \mathrm{~h}$. The number of inflammatory cells increased after 6 $\mathrm{h}$ and also persisted for more than $48 \mathrm{~h}$. The HCE prevented the muscle fiber damage induced by electrical stimulation, regardless of whether it was given before or after the acute exercise, and this was reflected in the decrease in macrophage density in the HCE administered rats.

Acute exercise induced the lipid peroxidation in all of the tissues studied, although there were differences in the kinetics of lipid peroxidation among the tissues. These differences have previously been described and it appears to be dependent on factors such as oxygen consumption, oxidant susceptibility and the activation of antioxidant enzymes and other repair systems [1]. Increased levels of lipid peroxidation have also been detected in the skeletal muscle of rats after acute [3] and long-term submaximal [4] exercise. However, supramaximal exercise may produce more ROS and be more damaging. In fact there is a larger increase in TBARS after high-intensity exercise in which lactate production is substantial when compared with moderate-intensity exercise $[3,30]$. Moreover, a significant relationship between the plasma lactate concentration and lipid peroxidation during progressive incremental exercise has been reported [31]. In agreement with this, lactate increases hydroxyl radical generation by the Fenton reaction resulting in lipid peroxidation [32]. Thus, the increase in lactate concentration seen here after acute exercise could account for the increase in TBARS levels detected in skeletal muscle.

The TBARS also increased in liver after $6 \mathrm{~h}$ and in brain after $48 \mathrm{~h}$ of acute exercise. In contrast, Kayatekin et al. [33] found that TBARS levels in the liver were unchanged after acute sprint exercise. Part of the reason for these contradictory findings could be attributed to the use of different types and intensities of exercise.

Our results also showed that lipid peroxidation induced by acute exercise were markedly higher in brain than in liver. In fact brain tissue has high content of oxidizable substrates, such as polyunsaturated fatty acids, poor catalase activity and low iron-binding capacity making it particularly prone to oxidative stress damage [1].

Although the HCE from P. emarginatus reduced TBARS formation in all of the tissues, it was most effective in TA muscle when administered at three different times before 


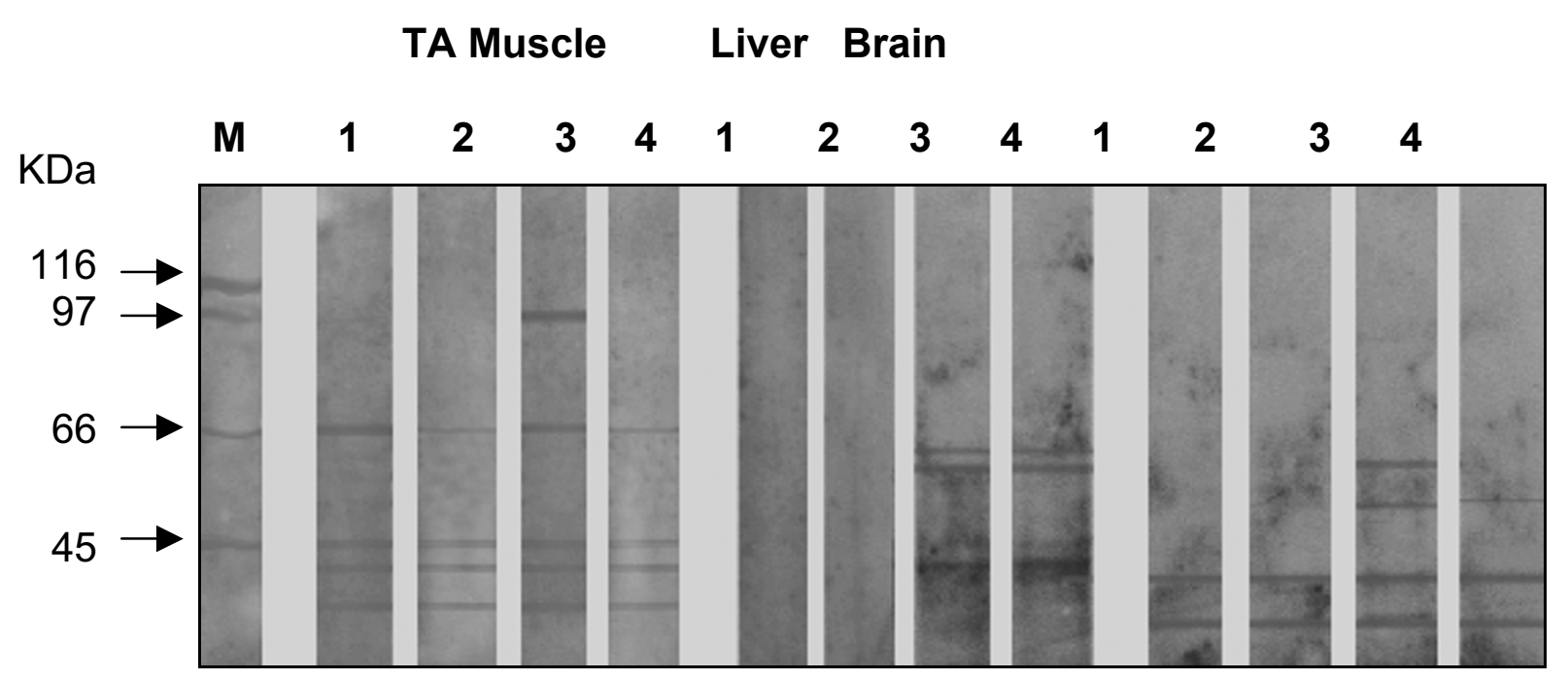

\section{Figure 5}

Western blot analysis for nitrotyrosine formation in brain, liver and TA muscle. M, molecular mass markers. Lane $\mathrm{I}$, rested control rats. Lane 2, rested control rats treated with HCE. Lane 3, acutely exercised rats. Lane 4, acutely exercised rats treated with HCE 24, 12 and 0.5 h before acute exercise. Nitrotyrosine formation was analyzed at I h (TA muscle), $6 \mathrm{~h}$ (liver) and $48 \mathrm{~h}$ (brain) after exercise. The results are representative of three independent experiments.

exercise. Thus, the decrease in MDA levels seen after administration of the HCE indicates that the extract has antioxidant activity. The higher level of HCE needed to prevent lipid peroxidation in TA muscle agreed with the greater levels of lipid peroxidation seen in this organ after electrical stimulation.

Nitrite is a stable metabolite of $\mathrm{NO}$ and can be used as an indicator of the overall formation of $\mathrm{NO}$ in vivo. Increased nitrite levels as a result of increased NOS activity have been observed in skeletal muscle after contractile activity [34]. In our study, acute exercise increased the nitrite levels in all of the tissues. In TA muscle, an increase on nitrite production and lipid peroxidation occurred within $1 \mathrm{~h}$ after acute exercise. However, in brain and liver, the increase in the levels of nitrite occurred at $48 \mathrm{~h}$ and $6 \mathrm{~h}$ after acute exercise, respectively and the lipid peroxidation increased after $6 \mathrm{~h}$ in the brain and liver. These findings indicate that despite the differences in time response of the organs to acute exercise, all of them suffered oxidative and nitrosative stress. Additionally, trauma caused by acute exercise in muscle was shown to be transferable to other organs. However, the highest levels of these com- pounds were detected in TA muscle, probably because it was the direct site of injury.

Our results also show that the basal nitrite level in TA muscle was five times greater than in brain and liver. This could be partly explained by the fact that skeletal muscle has a relatively high NOS activity compared with other organs [35]. Acute exercise increases NOS activity [8] and thus NO formation [7] in muscle. The increased nitrite formation seen after exercise could be mediated by increased intracellular calcium content of muscle fibers during contraction, which would activate NOS. Consistent with this is the observation that both of the constitutively expressed isoforms of NOS (eNOS and nNOS) require calcium as a cofactor for activation [36], and there is evidence that extracellular calcium may also enhance NOS activation during increased loading [37]. Thus, as calcium enters the sarcoplasm, not only does it induce muscle contraction, but it also activates calcium-dependent, constitutively expressed isoforms of NOS.

The HCE reduced nitrite production in TA muscle when administered before or after acute exercise. The extract was also effective in liver and brain tissues, where it decreased 
the nitrite formation induced by acute exercise. Our results for lipid peroxidation and nitrite formation agree with previous reports, indicating that the rate of NO production in rat liver is similar to the rate of superoxide anion production [38].

Determination of the protein nitrotyrosine content is frequently used to detect oxidative damage to tissues. Protein nitration has been suggested to be a final target of highly reactive nitrogen oxide intermediates (e.g. peroxynitrite) formed in reactions between $\mathrm{NO}$ and oxygen-derived species such as superoxide. Since NO is made by a variety of cell types, the opportunity for the formation of a tyrosine iminoxyl free radical exists in any protein in which tyrosyl radical formation occurs [13]. Additionally, myeloperoxidase and peroxidase can also oxidize nitrite to nitrogen dioxide radicals, which can participate in the nitration of tyrosine residues in protein [14]. Western blotting showed more than one band of nitrotyrosine in proteins in all of the tissues analyzed. Acute exercise increased nitrotyrosine formation in the tissues and HCE prevented the nitration of brain and skeletal muscle proteins. The reduction in nitrite levels and nitrotyrosine formation by HCE indicated that the extract prevented the production of reactive nitrogen species generated from the activity of NOS after acute physical exercise. In liver the HCE had no effect on protein nitration suggesting that, at least, part of the RNS formation and protein nitration in muscle are linked to phagocyte activity. As the HCE presented anti-inflammatory activity, it seemed also to prevent the secondary oxidative damage, caused by activated phagocytes.

The antioxidant action of the HCE could be partly explained by its terpene and phenol content [19]. Studies of the inhibition of lipid peroxidation have demonstrated a role of terpens and phenols $[39,40]$. Phenolic compounds have a high reactivity towards lipid peroxyl radicals and are thus able to interact with ROS to interrupt the propagation of lipid peroxidation [40]. Di Mascio et al. [41] showed that furan diterpenes isolated from an alcoholic extract of Pterodon sp had a high capacity to quench oxygen singlets but not to scavenge oxyradicals since the extract did not inhibit microssomal lipid peroxidation. A diterpene isolated of the plant Salvia miltiorrhiza was shown to inhibit lipid peroxidation in rat kidney and brain homogenates, and its activity was attributed to the presence of the furan ring in its structure [39]. In mouse brain, plant extracts containing polyphenols inhibited NMDA-induced lipid peroxidation and restored the glutathione levels [42].

Recently, nNOS was found to accommodate phenolic substituted compounds in its active site, indicating that such substances could act as inhibitors of nNOS and also as antioxidants [43]. Since the HCE contains phenolic constituents, this could explain the ability of the extract to inhibit nitrite formation in brain and muscle homogenates.

\section{Conclusion}

In conclusion, acute exercise induced by functional electrical stimulation in rats resulted in increase in TBARS, nitrite and nitrotyrosine levels in brain, liver and skeletal muscle and macrophage infiltration in muscle fibers. The HCE of $P$. emarginatus abolished most of these oxidative processes, thus providing for a high antioxidant and antiinflammatory action against acute exercise. Despite the well-documented protective role of plant antioxidant substances and their ability to protect against the deleterious effects of oxidation, most studies have examined the antioxidant effect of only one class of compound or of an isolated compound, mainly in vitro. Our results showed that a crude extract of $P$. emarginatus had anti-inflammatory, antioxidant and anti-nitrosative activities in vivo in various organs following acute exercise. Crude plant homogenates are generally less expensive to obtain and more accessible to the population than an isolated compound. Thus, our results support the beneficial effects of the Pterodon extract used popularly, and suggest its potential use in humans as a therapeutic agent against oxidative damage.

\section{Competing interests}

The author(s) declare that they have no competing interests.

\section{Authors' contributions}

FBAP carried out all of the experiments and participated in the drafting of the manuscript, PPA participated in the experiments of histological analysis, CMCPG supervised the work of FBAP and PPA, participated in the design drifting of the manuscript and IS coordinated the study and drafted the manuscript. All authors read and approved the final manuscript.

\section{Acknowledgements}

This work was partly supported by the Fundação de Amparo à Pesquisa do Estado de São Paulo (FAPESP) and by research fellowships from the Conselho Nacional de Desenvolvimento Científico e Tecnológico (CNPq) and Coordenação de Aperfeiçoamento de Pessoal de Nível Superior (CAPES).

\section{References}

I. Liu J, Yeo HC, Övervik-Douki E, Hagen T, Doniger SJ, Chyu DW, Brooks GA, Ames BN: Chronically and acutely exercised rats: biomarkers of oxidative stress and endogenous antioxidants. J App Physiol 2000, 89:2I-28.

2. Davies KJ, Quintanilha AT, Brooks GA, Packer L: Free radicals and tissue damage produced by exercise. Biochem Biophys Res Commun 1982, 107:1 1 98-1205.

3. Alessio HM, Goldfarb AH: Lipid peroxidation and scavenger enzymes during exercise: adaptive response to training. J Appl Physiol 1988, 64:1333-1336.

4. Sacheck J, Blumberg J: The role of vitamin $E$ and oxidative stress in exercise. Nutrition 200I, I7:809-8I4. 
5. Proske U, Morgan DL: Muscle damage from eccentric exercise: mechanism, mechanical signs, adaptation and clinical applications. J Physiol 200I, 537:333-345.

6. Marzatico F, Pansara O, Bertorelli L, Somenzini L, Della Valle G: Blood free radical antioxidant enzymes and lipid peroxides following long-distance and lactacidemic performances in highly trained aerobic and sprint athletes. J Sports Med Phys Fitness 1997, 37:235-239.

7. Jungersten $L$, Ambring $A$, Wall $B$, Wennmalm A: Both physical fitness and acute exercise regulate nitric oxide formation in healthy humans. J Appl Physiol 1997, 82:760-764.

8. Roberts CK, Barnard RJ, Jasman A, Balon TW: Acute exercise increases nitric oxide synthase activity in skeletal muscle. Am J Physiol 1999, 277:E390-E394.

9. Reid MB: Role of nitric oxide in skeletal muscle: synthesis, distribution and functional importance. Acta Physiol Scand 1998, 162:40I-409.

10. Stamler JS, Meissner G: Physiology of Nitric Oxide in Skeletal Muscle. Physiol Rev 2001, 81:209-237.

II. Davies KJ, Goldberg AL: Proteins damaged by oxygen radicals are rapidly degraded in extracts of red blood cells. J Biol Chem 1987, 262:8227-8234

12. Eiserich JP, Patel RP, O'Donnell VB: Pathophysiology of nitric oxide and related species: free radical reactions and modification of biomolecules. Mol Aspects Med 1998, 19:221-357.

13. Gunther MR, His LC, Curtis JF, Gierse JK, Marnett LJ, Eling TE, Mason RP: Nitric oxide trapping of the tyrosyl radical of prostaglandin $\mathbf{H}$ synthase-2 leads to tyrosine iminoxyl radical and nitrotyrosine formation. J Biol Chem 1997, 272: I7086-17090.

14. Hirota S, Takahama U, Ly TN, Yamauchi R: Quercetin-dependent inhibition of nitration induced by peroxidase/ $\mathrm{H} 2 \mathrm{O} 2 /$ nitrite systems in human saliva and characterization of an oxidation product of quercetin formed during the inhibition. J Agric Food Chem 2005, 53:3265-3272.

15. Correa MP: Dicionário de plantas úteis do Brasil e das exóticas cultivadas Ministério da Agricultura. Rio de Janeiro: Instituto Brasileiro de Desenvolvimento Florestal; 1984.

16. Mors WB, dos Santos Filho MF, Monteiro HJ, Gilbert B: Chomoprophylactic agent in Schistosomiasis: 14, I5-epoxygeranylgeraniol. Science 1967, 157:950-951.

17. Nunan EA, Carvalho MG, Piló-Veloso D, Turchetti-Maia RMM, Ferreira-Alves DL: Furane diterpenes with anti- and pro-inflammatory activity. Braz J Med Biol Res 1982, 1 5:450.

18. Duarte ID, Ferreira-Alves DL, Veloso DP, Nakamura-Craig M: Evidence of the involvement of biogenic amines in the antinociceptive effect of vouacapan extracted from Pterodon polygalaeflorus Benth. J Ethnopharmcol 1996, 55:13-18.

19. Mahjan JR, Monteiro MB: New diterpenoids from Pterodon emarginatus Vog. Anais Acad Bras Ciênc 1970, 42:103-107.

20. Carvalho JC, Sertié JA, Barbosa MV, Patrício KC, Caputo LR, Sarti SJ, Ferreira LP, Bastos JK: Anti-inflammatory activity of the crude extract from the fruits of Pterodon emarginatus Vog. Ethnopharmacol 1999, 64:127-133.

2I. Matsuura T, Ikata T, Takata S, Kashiwaguchi S, Niwa M, Sogabe T, Koga K: Effect of weight bearing on recovery from nerve injury in skeletal muscle. I Appl Physiol 200I, 9 I:2334-234I.

22. Moss DW: Clinical Enzymology. In Tietz Textbook of Clinical Chemistry 3rd edition. Edited by: Burtis CA, Ashwood ER. WB: Saunders Company; 1999:617-721.

23. Winterbourn CC, Gutteridge JM, Halliwell B: Doxorubicindependent lipid peroxidation at low partial pressures of $\mathrm{O}_{2}$. J Free Rad Biol Med 1985, I:43-49.

24. Scuro LS, Simioni PU, Gabriel DL, Saviani EE, Modolo LV, Tamashiro WMSC, Salgado I: Supression of nitric oxide production in mouse macrophage by soybean flavonoids accumulated in response to nitroprusside and fungal eliciation. $B M C$ Biochem 2004, 5:5-12

25. Bradford MM: A rapid and sensitive method for the quantification of microgram quantities of protein utilizing the principle of protein-dye binding. Anal Bioch 1976, 72:248-254.

26. Kanski J, Alterman MA, Schöneich C: Proteomic identification of age-dependent protein nitration in rat skeletal muscle. Free Radic Biol Med 2003, 35: I229-I239.

27. Pizza FX, Koh TJ, Mcgregor SJ, Brooks SV: Muscle inflammatory cells after passive stretches, isometric contractions, and lengthening contractions. J Appl Physiol 2002, 92:1873-1878.
28. Clarkson PM, Tremblay I: Exercise-induced muscle damage, repair, and adaptation in humans. J Appl Physiol 1988, 65:I-6.

29. Sacheck JM, Millbury PE, Cannon JG, Roubenoff R, Blumberg JB: Effect of vitamin $e$ and eccentric exercise on selected biomarkers of oxidative stress in young and elderly men. Free Rad Biol Med 2003, 34: I575-I588.

30. Salminen A, Vihko V: Lipid peroxidation in exercise myopathy. Exp Mol Pathol 1983, 38:380-388.

3I. Lovlin R, Cottle W, Pyke I, Kavanagh M, Belcastrom AN: Are indices of free radical damage related to exercise intensity? Eur J Appl Physiol Occup Physiol 1987, 56:313-316.

32. Halliwell B, Gutteridge JMC: Free Radicals in Biology and Medicine Oxford: Clarendon Press; 1989.

33. Kayatekin BM, Gonenc S, Acikgoz O, Uysal N, Dayi A: Effects of sprint exercise on oxidative stress in skeletal muscle and liver. Eur J Appl Physiol 2002, 87: 14I-I 44.

34. Reiser PJ, Kline WO, Vaghy PL: Induction of neuronal type nitric oxide synthase in skeletal muscle by chronic electrical stimulation in vivo. J App Physiol 1997, 82: 1250-1255.

35. Slater M, Knowles RG, Moncada S: Widespread tissue distribution, species distribution and changes in activity of $\mathrm{Ca}(2 \mathrm{I})$ dependent and $\mathrm{Ca}(2 \mathrm{I})$-independent nitric oxide synthases. FEBS Lett |99|, 29|:|45-|49.

36. Moncada S, Higgs A: The L-arginine-nitric oxide pathway. $N$ Engl] Med 1993, 329:2002-2012.

37. Stull M, Wehling M: Mechanical loading regulates NOS expression and activity in developing and adult skeletal muscle. Am J Physiol 1998, 275:C260-C266.

38. Giulivi C, Poderoso JJ, Boveris A: Production of nitric oxide by mitochondria. J Biol Chem 1998, 273: I I038-I I043.

39. $\mathrm{Ng} \mathrm{TB}$, Liu F, Wang ZT: Antioxidant activity of natural products from plants. Life Sci 2000, 66:709-723.

40. Noguchi N, Niki E: Phenolic antioxidants: a rationale for design and evaluation of novel antioxidant drug for atherosclerosis. Free Rad Biol Med 2000, 28:1538-1546.

4I. Di Mascio PD, Medeiros MHG, Sies H, Bertolotti S, Braslavsky SE, Piló Veloso D, Sales BHLN, Magalhães E, Braz-Filho R, Bechara EJH: Quenching of singlet molecular oxygen by natural furan diterpenes. J Photochem Photobiol B: Biology 1997, 38:169-173.

42. Lee KJ: Protective effect of vegetable extracts on oxidative stress in brain of mice administered with NMDA. Food Res Int 2002, 35:55-63.

43. Auvin S, Auget M, Navet E, Harnett JJ, Viossat I, Schulz J, Bigg D, Chabrier Pierre-E: Novel inhibitors of neuronal nitric oxide sythase with potent antioxidant properties. Bioorg Med Chem Let 2003, 13:209-2/2.

\section{Pre-publication history}

The pre-publication history for this paper can be accessed here:

http://www.biomedcentral.com/1472-6882/5/17/prepub

Publish with Biomed Central and every scientist can read your work free of charge

"BioMed Central will be the most significant development for disseminating the results of biomedical research in our lifetime. "

Sir Paul Nurse, Cancer Research UK

Your research papers will be:

- available free of charge to the entire biomedical community

- peer reviewed and published immediately upon acceptance

- cited in PubMed and archived on PubMed Central

- yours - you keep the copyright

Submit your manuscript here:

http://www.biomedcentral.com/info/publishing_adv.asp
BioMedcentral 